\title{
Pulmonary Veno-occlusive Disease
}

\author{
K. WEISSER, F. WYLER, and F. GLOOR \\ From the Departments of Paediatrics and Pathology, University of Basle, Switzerland
}

Pulmonary venous congestion with or without 'reactive' or 'protective' pulmonary arterial hypertension (Wood, 1954; Wood, Besterman, Towers, and McIlroy, 1957) is most commonly caused by left heart disease. The obstruction to blood flow may, however, also be located upstream to the left atrium. Among the known causes of such obstruction are compression of the pulmonary veins by a mediastinal mass (Edwards and Burchell, 1951; Andrews, 1957; Evans, 1959); congenital stenosis of the pulmonary veins at the veno-atrial junction (Lucas, Woolfrey, Anderson, Lester, and Edwards, 1962); or thrombus formation in the pulmonary veins due to greatly reduced blood flow associated with congenital pulmonary stenosis (Rich, 1948; Best and Heath, 1958).

An isolated, primary, obstructive disease of the small and medium-sized pulmonary veins has been described and variously named isolated pulmonary venous sclerosis, obstructive disease of the pulmonary veins, and recently pulmonary veno-occlusive disease (Höra, 1934; Massachusetts General Hospital, 1937; Grainger, 1958; Crane and Grimes, 1960; Brewer and Humphreys, 1960; Bürki, 1963; Stovin and Mitchinson, 1965; Brown and Harrison, 1966; Heath, Segel, and Bishop, 1966). Because of its rarity a further case is presented.

\section{Case Report}

S.E., a 15-year-old girl, a child of healthy parents, was born after an uncomplicated pregnancy. At delivery the mother had a temperature of $40^{\circ} \mathrm{C}$., which was attributed to hypersensitivity to quinine given as a labour-inducing drug. The delivery was otherwise normal and the baby was well at birth. Growth and development in early infancy were normal. She had pertussis at the age of 6 months, and later rubella, varicella, and mumps, and uncomplicated otitis media on 2 occasions. She had been immunized against poliomyelitis.

In May 1961, at the age of 14 , the girl was seen by a physician for the first time because of dyspnoea on exertion. The only finding then was a transient tachycardia. ESR and urinalysis were normal. No chest film or electrocardiogram was obtained at that

Received September 12, 1966. time. She gradually became more dyspnoeic, with increasing weakness and fatigue, and her weight fell.

In October 1961 she developed jaundice with acholic stools and dark urine. Infective hepatitis was diagnosed, and she was put on a diet and, 2 weeks later, on corticosteroids. She had had no known contact with a case of hepatitis. Again, except for her dyspnoea, no cardiac or pulmonary abnormality was found. The icterus decreased very slowly, but never disappeared entirely. In the following months her general condition deteriorated and she was breathless even at rest. On two occasions she had syncopal attacks lasting a few minutes. She lost $12 \mathrm{~kg}$. within one year. In January 1962 the parents finally consented to her being admitted to hospital.

On admission she was obviously ill, wasted, jaundiced, cyanotic, and severely dyspnoeic and orthopnoeic.

Cardiovascular system. The heart rate was 140 , with a marked right ventricular heave. On auscultation there was a normal first sound, an ejection click, and a very loud second sound over the pulmonary artery. Splitting of the second sound was imperceptible over the base and was very narrow at the lower sternal border. A diastolic decrescendo murmur was heard over the pulmonary area. The peripheral pulses were unchanged, the blood pressure was $120 / 80 \mathrm{~mm}$. $\mathrm{Hg}$. The neck veins were slightly distended, with a not very marked a-wave. The liver edge was palpable $8 \mathrm{~cm}$. below the right costal margin; it was firm and not tender. There was no splenomegaly. The extremities were cold and livid, with no oedema.

Lungs. The respiratory rate was moderately increased, the child being severely orthopnoeic, but having no cough or sputum. At the lung bases there were numerous râles.

Chest $x$-ray film. This showed a moderately enlarged right ventricle and right atrium, and distension of the pulmonary artery and its proximal branches. The peripheral pulmonary vasculature seemed to be reduced. The left ventricle and particularly the left atrium were not enlarged. Slight mottling was noted in the lower lung fields, the hilar shadows were increased in size. Fine interlobar fissure lines were apparent. In addition, there were numerous prominent lines consistent with A and $B$ lines as described by Kerley (1933) in the upper and lower lung fields, respectively (Fig. 1).

Electrocardiogram was consistent with massive right 
ventricular hypertrophy and also showed $S-T$ changes (AQRS $110^{\circ}$, AT $40^{\circ}$ ). There was a P pulmonale.

Phonocardiogram confirmed the auscultatory findings and substantiated the diagnosis of pulmonary hypertension. There was a pulmonary ejection click after a normal first heart sound, a very loud second sound without splitting over the base, but with narrow splitting at the lower left sternal border. A short, high-pitched, early systolic murmur and a diastolic murmur, also of high frequency, beginning after the second sound and decreasing in amplitude, were recorded as acoustic evidence of relative tricuspid and pulmonary valve incompetence. Dye dilution curve (antecubital injection and detection with an ear-piece) revealed a slightly prolonged appearance time, as well as a moderately prolonged dilution time, expressions of a reduced minute volume, and valvular incompetence. Significant anatomical right-to-left shunting could be excluded.

The patient's bad condition rendered further haemodynamic or respiratory studies impossible.

Laboratory findings. ESR $3 \mathrm{~mm}$./hr.; WBC 13, $800 /$ c.mm., with normal differential ; $\mathrm{Hb} 14 \cdot 2$ g. $/ 100 \mathrm{ml}$., RBC 4.66 mill., 172,000 platelets/c.mm., $4 \cdot 2 \%$ reticulocytes. Serum bilirubin $4.4 \mathrm{mg} . / 100 \mathrm{ml} ., 82 \%$ indirect. Osmotic resistance of the erythrocytes, normal. PriceJones curve slightly shifted toward microcytosis. Serum iron $106 \mu \mathrm{g} .100 \mathrm{ml}$. Liver function tests: total protein, electrophoresis, and cholesterol normal. SGOT 42 units, SGPT 28 units. Alkaline phosphatase $10 \cdot 2$ units. Bromsulphalein excretion test, $13 \cdot 7 \%$ retention after 30 minutes. Prothrombin concentration $47 \%$, with no increase after administration of vitamin $\mathrm{K}$.

No bilirubin in the urine; normal excretion of urobilin in urine and stools. Liver biopsy, normal liver tissue. Urinalysis, serum electrolytes, urea, and acidbase status normal. Urine 17-keto- and 17-hydroxysteroids, and gonadotrophins normal. Bacteriology of nasal and pharyngeal smears, stools, urine, and blood cultures, negative. Tuberculin reactions, Widal reaction, and agglutinations for leptospirosis and brucellosis, negative. The stools gave no cytopathogenic effect on tissue culture. Antistreptolysin titre 120 units. The latex fixation and LE tests, and Coombs test negative.

Hospital course. Treatment consisted essentially of digitalization, diuretics, oxygen, corticosteroids, and antibiotics. After temporary improvement of the dyspnoea and icterus, the child deteriorated and she died 8 weeks after admission.

Necropsy. Body length normal $(153 \mathrm{~cm}$.) but severely wasted ( $37 \mathrm{~kg}$.). Heart greatly enlarged $(297 \mathrm{~g}$.) and spherical, the apex being formed by the right ventricle. Right atrium and auricle, dilated. Foramen ovale and ductus arteriosus, closed. Right ventricle very enlarged, with massive hypertrophy of the myocardium, its thickness measuring $10 \mathrm{~mm}$. in the region of the pulmonary outflow tract. Circumference of tricuspid valve measured $10 \mathrm{~cm}$. Left ventricle rather small, the thickness of the wall being $10 \mathrm{~mm}$. just below the mitral valve which was normal. Left atrium also small, with smooth endocardium. Coronary system normal.

Lungs, normal lobe formation, firm, large, and heavy (right 422 g., left 407 g.). Cut surface reddish-brown, congested, and oedematous, with reduced air content. Bronchial mucosa greyish-red and covered by some mucus. There were no effusions or adhesions of the pericardium or pleura.

Pulmonary artery and its proximal branches considerably distended; they contained no thrombi. On the intima were some yellow plaques. Pulmonary veins patent, of normal calibre, walls not thickened.

Aorta and venae cavae normal. Liver showed lobular markings, with reddish areas of congestion and atrophy in the lobular centre.

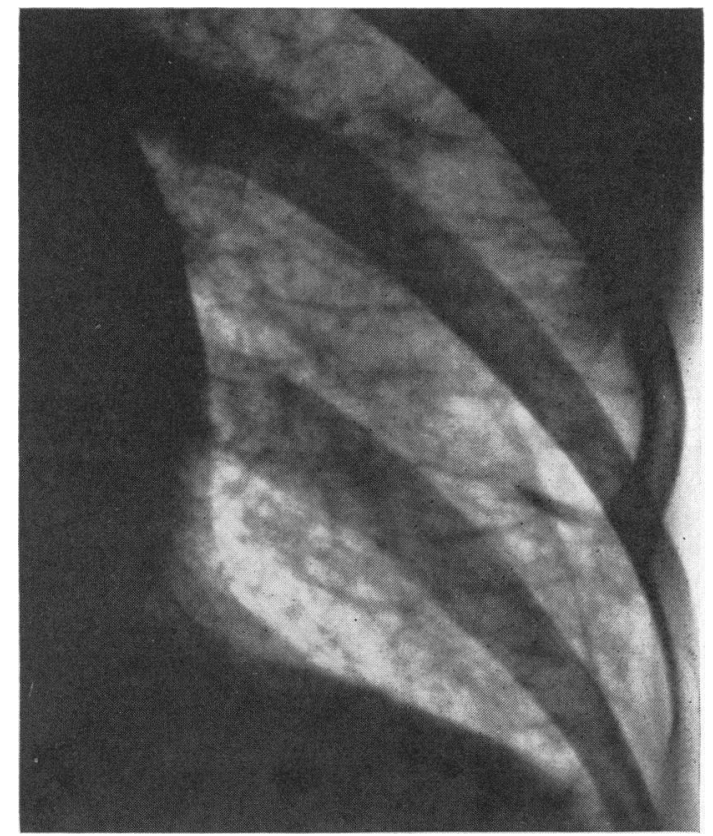

Fig. 1.-_B-lines' of Kerley in the lower lung field.

Histology. The lungs were evenly inflated. The alveolar septa were enlarged, with chronic congestion and fibrosis. Macrophages containing haemosiderin were present in the septa, and within the alveolar spaces. Some alveoli contained fluid, others erythrocytes. The large and medium-sized arteries of both lungs showed yellow intimal streaks and plaques, with intimal fibrosis, deposition of lipids, and splitting of the elastic fibres. In some places the media was reduced in thickness. There was some fibrosis of the adventitia. Inflammation was absent. The small muscular pulmonary arteries and arterioles showed conspicuous medial hypertrophy, and splitting of the internal elastic lamina. 'Onionskin' concentric thickening of the intima was seen in the 


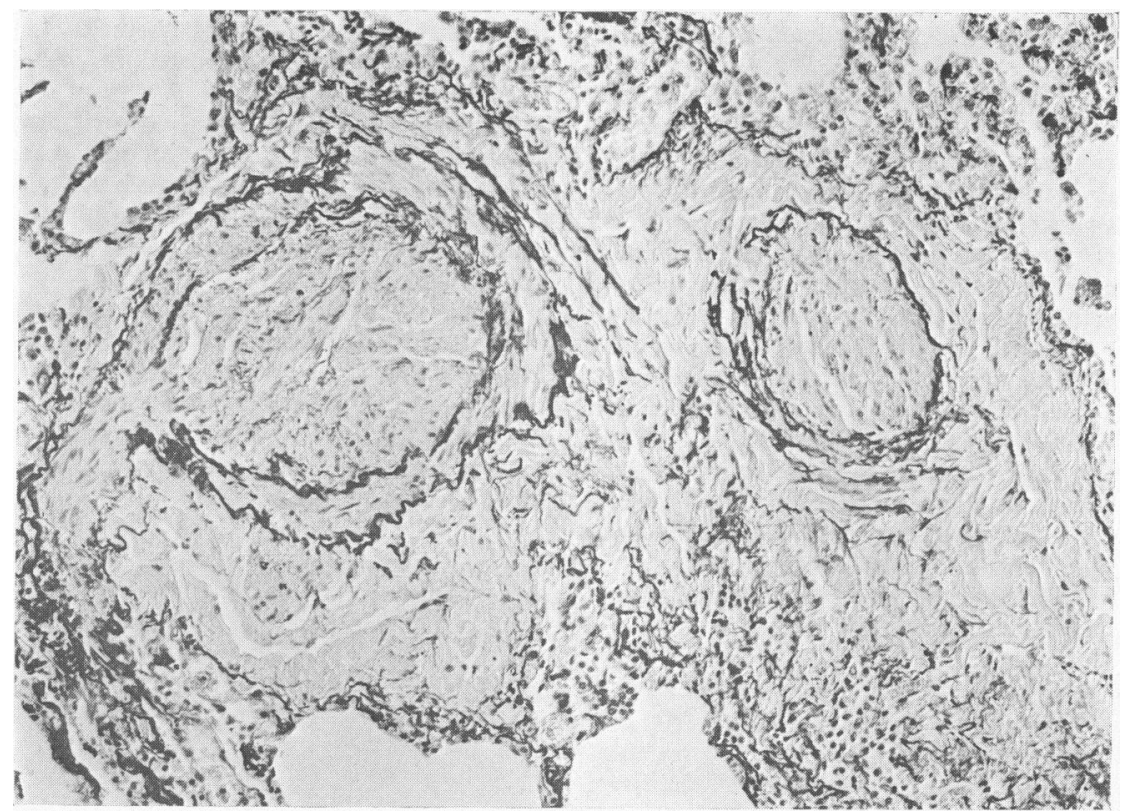

FIG. 2.-Complete obliteration of 2 small pulmonary veins by loose connective tissue. Fibrosis of the adventitia. (Weigert's Resorcin-Fuchsin elastic stain. $\quad \times 120$.

smallest arteries, but without complete obliteration. In a few areas there was fibrinoid necrosis of the vessel wall. There was no thrombosis.

The walls of the bronchial arteries were normal. The peribronchial venous plexus was over developed, with dilatation and coiling of the bronchial veins, the walls of which were moderately sclerotic. There were numerous anastomoses into pulmonary veins, originating from the periphery of the lobules.

The pulmonary veins presented marked coiling. The large pulmonary veins were normal, but the medium-sized and small pulmonary veins, and the venules were completely obliterated in most places (Fig. 2). Their lumen was filled by an almost acellular fibrous tissue, partly of compact collagenous, partly of loose reticular structure. In this fibrous tissue some very fine elastic fibres were recognizable. Some of the obliterated veins were recanalized (Fig. 3); in others there was incomplete obliteration by homogeneous and almost acellular plaques (Fig. 4) which seemed to represent early stages of the obliterating process. These plaques contained little collagenous tissue but many reticular fibres. The tissue was loosened by oedema and was formed by colourless ground substance, which did not stain either with Astra BluePAS for acid and neutral mucopolysaccharides, or with the Weigert stain for fibrin, or with Congo Red. The elastic fibres could not be impregnated with iron. The media of the veins was thin in some places, its smooth muscle atrophied and often replaced by collagenous fibres. The adventitia showed severe fibrosis (Fig. 2). Inflammation of the venous wall was absent. Vascular pathology, particularly of the veins, was strictly limited to the lungs.

\section{Discussion}

The auscultatory findings of the heart together with a history of repeated syncopal attacks, and the cyanosis and cold of the extremities led to a diagnosis of severe pulmonary hypertension. This was supported by the ECG and the phonocardiogram, and suggested that the pulmonary systolic pressure probably exceeded $100 \mathrm{~mm}$. Hg. The chest film also showed the classical picture of pulmonary arterial hypertension.

The history of increasing dyspnoea and orthopnoea and the presence of râles at the lung bases were evidence of pulmonary congestion. The presence of numerous 'Kerley lines' throughout the lung fields on $x$-ray film indicated pulmonary interstitial oedema (Fig. 1), such lines having been attributed to enlargement of the interlobular septa by dilatation of the lymph vessels, interstitial oedema, and fibrosis (Grainger, 1958; Stender and Schermuly, 1961). Lastly, the presence of pulmonary congestion without radiographic signs of left atrial enlargement and without distension of the large pulmonary veins was in keeping with a diagnosis of pulmonary venoocclusive disease.

Final confirmation of this diagnosis requires the demonstration of an increased pulmonary wedge pressure together with a normal left atrial pressure at heart catheterization, and a lung biopsy. Neither 


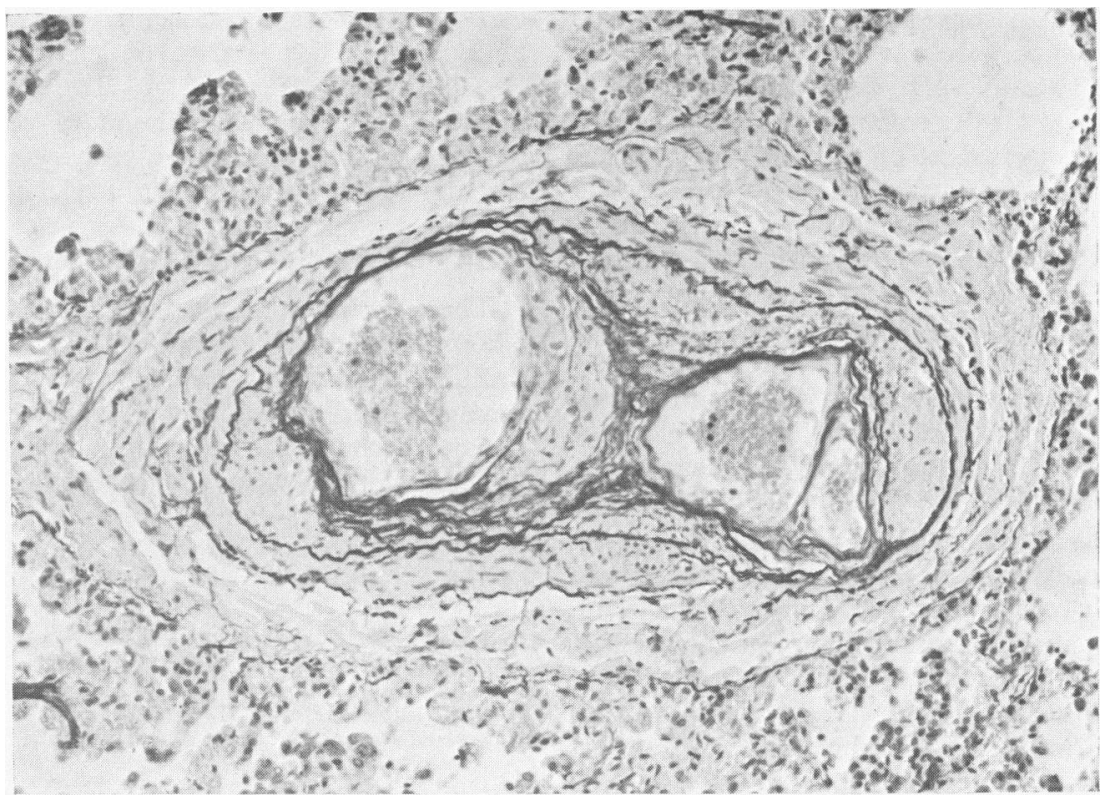

FIG. 3.-Small pulmonary vein with subdivision of the lumen (recanalization ?). (Weigert's Resorcin-Fuchsin elastic stain. $\times 160$.)

examination could be performed in the present case because of the patient's poor condition.

Descriptions of 9 cases of veno-occlusive disease of the lung, ranging in age from 5 to 48 years, have already been published. The disease has always proved fatal, with a duration from the onset of symptoms until death of from 7 weeks up to 5 years.

The aetiology of this condition remains obscure,

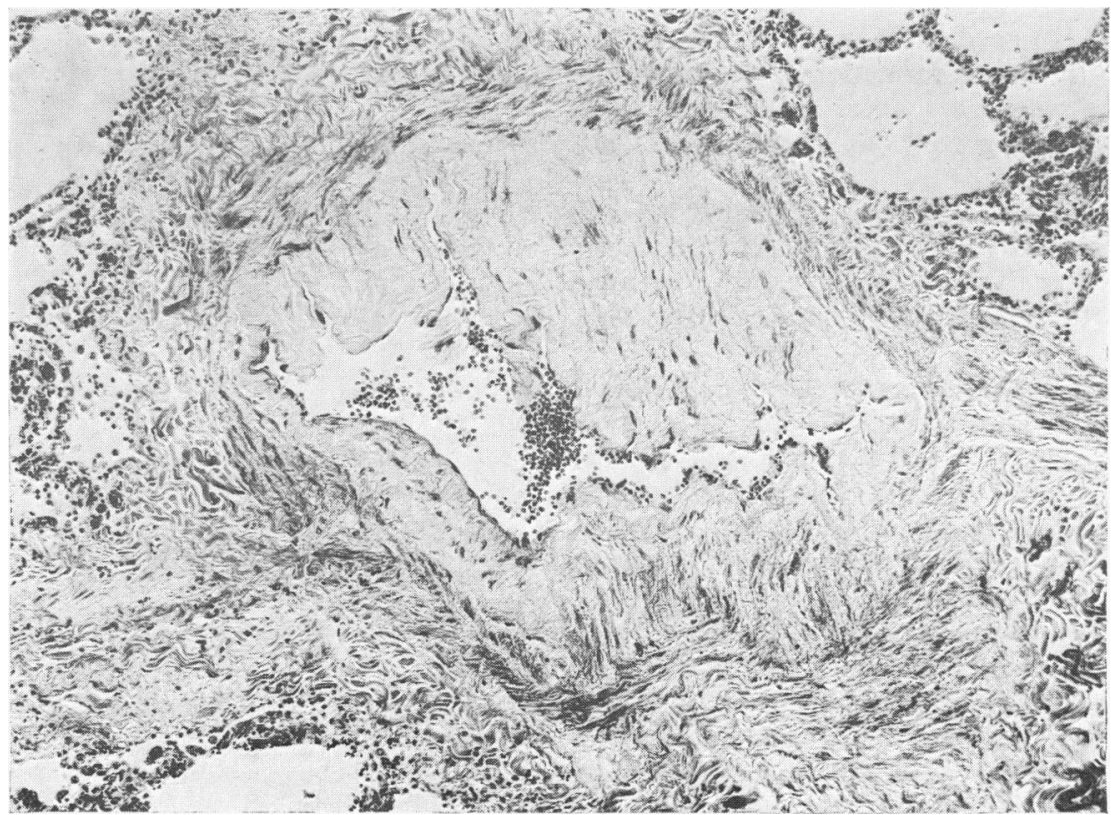

FIG. 4.-Pulmonary vein with homogeneous plaque formation. (H. and $E . \quad \times 100$.) 
our laboratory findings confirming the negative results of others. Recognized bacterial, viral, allergic, or auto-allergic aetiologies could be excluded. Tests for the collagen diseases were also negative. The presence of jaundice, with dark urine and acholic stools, was a feature of our case: the icterus decreased after treatment with corticosteroids but never disappeared entirely. At death 6 months later, the liver showed chronic congestion, but no inflammation. We cannot exclude a coincident infective hepatitis. The icterus may also have been caused by right heart failure with liver congestion. Probably the icterus has no relevance to the pathogenesis of the primary process in the pulmonary veins.

Brown and Harrison (1966), summarizing the published reports on 10 cases, noted that 4 had predominantly collagenous thickening of the venules, 3 had predominant thrombosis of the pulmonary veins, and 3 had a mixture of both. In one of these 10 cases (Manzini, 1947) pulmonary venous thrombosis was not an isolated occurrence but part of a generalized thrombophlebitis, and this case therefore should not be included in the entity of pulmonary veno-occlusive disease. In our patient the process was strictly limited to the small and medium-sized veins and consisted of various stages of obliteration by intimal proliferation (Fig. 2 and 4), without any thrombus formation. The intimal proliferation, therefore, presumably represents the primary process. Increasing obstruction of the small veins leads to reduction in blood flow, which could lead to thrombus formation in the mediumsized and large pulmonary veins, as was found in all the adult patients reported but in only one of the children (Grainger, 1958).

In a few places we found signs of recanalization of the small obliterated veins (Fig. 3). Whether this is a proof of earlier thrombosis, or whether it could also develop after obliteration by intimal thickening remains undecided.

The nature of the lesion may be solved by the fluorescent antibody technique. Using this technique in veno-occlusive disease of the liver (BuddChiari syndrome) of the type observed in Jamaica, Stirling, Bras, and Urquhart (1962) were thereby able to show that the early venous lesion did not contain fibrin and, therefore, could not be the result of primary thrombosis.

The analogy between pulmonary veno-occlusive disease and the Budd-Chiari syndrome of the liver is striking. The aetiology of the latter is unknown in most instances; but veno-occlusive disease of the liver in Jamaica and in South Africa has been shown to be caused by Senecio alkaloids contained in certain 'bush-teas' (Schoental and Magee, 1957; Schoental, 1963; Stuart and Bras, 1957; Bras, Brooks, and Watler, 1961). The similarity of the primary lesion in the pulmonary veins raises the question as to whether pulmonary veno-occlusive disease could be due to a toxic agent, possibly inhaled.

\section{Summary}

The case of a 15-year-old girl is described in whom there was a primary process of intimal proliferation causing obliteration of the small and medium-sized pulmonary veins, leading to interstitial oedema of the lung and to pulmonary arterial hypertension. 9 cases of this fatal disease have been recorded; the aetiology is unknown.

\section{REFERENCES}

Andrews, E. C., Jr. (1957). Five cases of an undescribed form of pulmonary interstitial fibrosis caused by obstruction of the pulmonary veins. Bull. Fohns Hopk. Hosp., 100, 28.

Best, P. V., and Heath, D. (1958). Pulmonary thrombosis in cyanotic congenital heart disease without pulmonary hypertension. F. Path. Bact., 75, 281.

Bras, G., Brooks, S. E. H., and Watler, D. C. (1961). Cirrhosis of the liver in Jamaica. ibid., 82, 503.

Brewer, D. B., and Humphreys, D. R. (1960). Primary pulmonary hypertension with obstructive venous lesions. Brit. Heart $\mathcal{F}$., 22, 445.

Brown, C. H., and Harrison, C. V. (1966). Pulmonary venoocclusive disease. Lancet, 2,61 .

Bürki, K. (1963). Eine primäre isolierte obliterierende Pulmonalvenenveränderung als Ursache eines chronischen Cor pulmonale. Arch. Kreisl.-Forsch., 40, 35.

Crane, J. T., and Grimes, O. F. (1960). Isolated pulmonary venous sclerosis: a cause of cor pulmonale. $\mathcal{f}$. thorac. cardiovasc. Surg., 40, 410.

Edwards, J. E., and Burchell, H. B. (1951). Multilobar pulmonary venous obstruction with pulmonary hypertension. 'Protective' arterial lesions in the involved lobes. Arch. intern. Med., 87, 372.

Evans, W. (1959). The less common forms of pulmonary hypertension. Brit. Heart f., 21, 197.

Grainger, R. G. (1958). Pulmonary hypertension: a symposium. III. Interstitial pulmonary oedema and its radiological diagnosis. A sign of pulmonary venous and capillary hypertension. Brit. F. Radiol., 31, 201.

Heath, D., Segel, N., and Bishop, J. (1966). Pulmonary venoocclusive disease. Circulation, 34, 242.

Höra, J. (1934). Zur Histologie der klinischen 'primăren Pulmonalsklerose'. Frankfurt. Z. Path., 47, 100.

Kerley, P. (1933). Radiology in heart disease. Brit. med.f., 2, 594.

Lucas, R. V., Jr., Woolfrey, B. F., Anderson, R. C., Lester, R. G., and Edwards, J. E. (1962). Atresia of the common pulmonary vein. Pediatrics, 29, 729.

Manzini, C. (1947). Endophlebitis obliterans universalis, vorwiegend der Lungenvenen, mit konsekutivem Cor pulmonale. Schweiz. Z. Path., 10, 309.

Massachusetts General Hospital (1937). Case records : case 23511. New Engl. F. Med., 217, 1045.

Rich, A. R. (1948). A hitherto unrecognized tendency to the development of widespread pulmonary vascular obstruction in patients with congenital pulmonary stenosis (tetralogy of Fallot). Bull. Fohns. Hopk. Hosp., 82, 389.

Schoental, R. (1963). Liver disease and 'natural' hepatotoxins. Bull. Wld Hlth Org., 29, 823.

-, and Magee, P. N. (1957). Chronic liver changes in rats after a single dose of lasiocarpine, a pyrrolizidine (Senecio) alkaloid. f. Path. Bact., 74, 305.

Stender, H. St., and Schermuly, W. (1961). Das interstitielle Lungenödem im Röntgenbild. Fortschr. Röntgenstr., 95, 461. 
Stirling, G. A., Bras, G., and Urquhart, A. E. (1962). The early lesions in veno-occlusive disease of the liver. Arch. Dis. Childh., 37, 535.

Stovin, P. G. I., and Mitchinson, M. J. (1965). Pulmonary hypertension due to obstruction of the intrapulmonary veins. Thorax, $20,106$.

Stuart, K. L., and Bras, G. (1957). Veno-occlusive disease of the liver. Quart. F. Med., 26, 291.

Wood, P. (1954). An appreciation of mitral stenosis. Part I. Clinical features. Part II. Investigations and results. Brit. med. F., 1, 1051 and 1113.

_, Besterman, E. M., Towers, M. K., and McIlroy, M. B. (1957). The effect of acetylcholine on pulmonary vascular resistance and left atrial pressure in mitral stenosis. Brit. Heart f., 19, 279.

The following articles will appear in future issues of this journal:

Blood Lead Levels in Normal and Mentally Deficient Children. By Sheila L. M. Gibson, C. N. Lam, W. M. Macrae, and A. Goldberg.

Sarcoidosis with Polyarthritis in a Child. By A. Th. Schweizer and P. Kanaar.

Arthrogryposis Accompanying Congenital Spinal-type Muscular Atrophy. By Michael Besser and Albert Behar.

Fulminating Diabetes with Lymphocytic Thyroiditis. By L. Crome, Magda Erdohazi, and R. P. A. Rivers. Crohn's Disease of the Jejunum in Children. By A. R. Chrispin and E. Tempany

Cells in the Urine of Newborn Infants. By Hilton Silver, J. C. Drever, and D. M. Douglas.

Wiskott-Aldrich Syndrome. By R. N. Srivastava.

Plasma and Urinary Amino Acids in Children with Primary Hyperoxaluria and in Normal Children. By Dorothy A. Gibbs, C. J. Thompson, and R. W. E. Watts.

Methylmalinic Aciduria. An Inborn Error of Metabolism Leading to Chronic Metabolic Acidosis. By V. G. Oberholzer, B. Levin, E. Ann Burgess, and Winifred F. Young.

Glucose-galactose Malabsorption. By J. M. Abraham, B. Levin, V. G. Oberholzer, and Alex Russell.

Serum Magnesium Level in Infants and Children with Hepatic Diseases. By Akio Kobayashi and Kazuo Shiraki.

Spontaneous Intrauterine Decapitation. By L. M. Swinburne.

Paroxysmal Dyskinesia. A Case Responsive to Benztropine Mesylate. By George R. Mushet and F. E. Dreifuss.

Experiences with Radioisotope Renography in Children. By J. H. Johnston and Irene M. Irving.

Low Mitotic Activity of Peripheral Lymphocytes During First Two Years of Life. By Nicholas Matsaniotis, Cleopatra Economou-Mavrou, and Christine Tsenghi.

Neonatal Haemothorax-A Report of 2 Cases. By J. P. Grausz and D. R. Harvey.

Jejunal Biopsy in Infants and Underweight Children. By Alexander S. McNeish.

Listeriosis in Association with Esch. coli Meningitis. By P. Curtis and P. A. Lamport. 